\title{
Safety verification of genetically modified rice morphology, hereditary nature, and quality
}

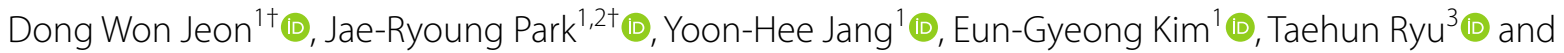 \\ Kyung-Min $\mathrm{Kim}^{1,2^{*}}$
}

\begin{abstract}
Background: The drought environment occurs frequently due to the unpredictable future climate change, and drought has a direct negative impact on crops, such as yield reduction. Drought events are random, frequent, and persistent. Molecular breeding can be used to create drought-tolerant food crops, but the safety of genetically modified (GM) plants must be demonstrated before they can be adopted. In this research, the environmental risk of drought-tolerant GM rice was explored by assessing phenotype and gene flow. Drought resistance genes CaMsrB2 inserted HV8 and HV23 were used as GM rice to analyze the possibility of various agricultural traits and gene flow along with non-GM rice.

Results: When the traits 1000-grain weight, grain length/width, and yield, were compared with GM rice and non-GM rice, all agricultural traits of GM rice and non-GM rice were the same. In addition, when the germination rate, viviparous germination rate, pulling strength, and bending strength were compared to analyze the possibility of weediness, all characteristic values of GM rice and non-GM rice were the same. Protein, amylose, and moisture, the major nutritional elements of rice, were also the same.

Conclusions: The results of this research are that GM rice and non-GM rice were the same in all major agricultural traits except for the newly assigned characteristics, and no gene mobility occurred. Therefore, GM rice can be used as a means to solve the food problem in response to the unpredictable era of climate change in the future.
\end{abstract}

Keywords: Drought, Rice, Environmental risk, Gene flow, Genetically modified organism, Yield

\section{Background}

Drought is a major constraint factor in rice production across Asia and sub-Saharan Africa. Continued drought in regions or countries that depend on rainfall for irrigation results in a decrease in rice production [1]. The drought index, which includes the frequency, duration, severity, scale, and the risk of drought in South Korea, is expected to increase significantly in the future [2]. Therefore, it is important not only to establish an irrigation

\footnotetext{
${ }^{*}$ Correspondence: kkm@knu.ac.kr

${ }^{\dagger}$ DongWon Jeon and Jae-Ryoung Park contributed equally to this work

${ }^{1}$ Division of Plant Biosciences, School of Applied Biosciences, College

of Agriculture and Life Science, Kyungpook National University,

Daegu 41566, Korea

Full list of author information is available at the end of the article
}

system, but also to secure a drought-tolerant genetic resource through the expansion of the fundamental plant gene pool in Korea.

Traditional and molecular breeding methods can be used to create drought-tolerant varieties. Molecular breeding has become popular for its economic and efficiency advantages in facilitating the insertion of foreign genes, short gene fixation period, and the establishment of a strong phenotype [3]. However, the lack of understanding of the potential effects of genetic modification of food crops on the human body and environment has prompted many regulatory limits on molecular breeding [4]. Risk assessments are required to determine the toxicity of insertion proteins, the potential for allergies, comparative assessments of nutrients and metabolites, environmental emissions, the potential for weediness, 
natural survival, reproductive capacity, and molecular biological characterization of the insertion, location, and expression of the introduced genes [5]. In addition, several environmental groups are currently concerned about unwanted environmental and ecological changes due to the development of GM crops [6]. It is believed that one of the causes of ecosystem destruction is that from GM crop to non-GM crop, superweeding plants will be born due to introgression of gene flow and transgenes due to pollen. However, many studies have already demonstrated that hybridization does not occur and gene flow does not occur between GM plants and non-GM plants $[7,8]$. As a result of these studies, the diversity of GM crops has increased, and GM crops that meet the needs of consumers are continuously being developed in response to the rapidly changing climate change [9]. Nevertheless, citizens' anxiety about GM crops still exists, and it is urgent to establish environmental risk assessment standards and frame that can alleviate these concerns [10].

Environmental risk and molecular biological characteristics must be assessed over broad areas because biological activity varies widely with varying environmental conditions [11]. The Korean government has designated risk assessment agencies to evaluate the long-term safety of GM organisms (GMOs).

Field research should be based on collecting information about the environment in which the research is conducted. Environmentally influenced phenotypic data are meaningless for comparisons of absolute values in different environments [12]. Therefore, recording and analyzing environmental figures can be used not only for this study, but also as data that provide the scientific justification and experimental validity of additional studies with similar research purposes.

In this study, we compared the agronomic characteristics of the parent and transgenic plants to assess the effect of the environment on morphogenetic variations other than the foreign gene effect. Weediness potential was assessed by performing shattering, viviparous measurement, and survivability tests in the natural environment. Studies included natural cold treatment germination rate measurement and horizontal and vertical gene transfer tests. The results can be used as a basis for the preparation of big data for environmental safety assessments of other GM rice varieties with similar reproductive mechanisms. In this study, to analyze that GM rice and non-GM rice are not different, evaluation of agricultural traits and weeding potential were performed. In addition, various analysis items used in this study can be used as important items to evaluate the stability of GM plants in the future.

\section{Materials and methods Plant materials}

The HV8 and HV23 varieties carry a CaMsrB2 gene insertion that functions as a defense regulator against oxidative stress in Ilmi (Oryza sativa spp. japonica cv. Ilmi) $[13,14]$. HV8 and HV23 used in this research were obtained from Oh et al. [13, 15]. The parent plant Ilmi and five testing rice cultivars (Oryza sativa L.) such as Samgang, Beakjinju, Junam, Nagdong, and Ilpum were obtained from Prof. Kyung-Min Kim at Plant Molecular Breeding laboratory (Kyungpook National University in Korea) and cultured in the GM fields of Kyungpook National University at Gunwi in Korea $\left(36^{\circ} 6^{\prime} 41.54^{\prime \prime} \mathrm{N}\right.$, $\left.128^{\circ} 38^{\prime} 26.17^{\prime \prime} \mathrm{E}\right)$.

\section{Environmental data collection}

This experiment was conducted in the GM field $\left(4700 \mathrm{~m}^{2}\right.$, $36^{\circ} 6^{\prime} 46.13$ “ N, $128^{\circ} 38^{\prime} 25.21$ "E) in Gunwi, Korea. Plants were planted at $30 \times 15 \mathrm{~cm}$ planting distance. The fertilizer consisted of $\mathrm{N}-\mathrm{P}_{2} \mathrm{O}_{5}-\mathrm{K}_{2} \mathrm{O}\left(9.04 .5-5.7 \mathrm{~kg} 10 \mathrm{a}^{-1}\right)$ according to the rice standard culture method of the Rural Development Administration.

The daily mean temperature, relative humidity, and rainfall were recorded through the agricultural meteorological observation system of the rural development administration of Korea, and wind direction and speed were measured at 30-min intervals using the wind direction anemometer located in the GM field. A drought field was constructed to measure the difference in weediness potential and agronomic characteristics as it relates to the expression of the CaMsrB2 gene and the cultivation environment. The drought field was constructed with sloped silt $2 \mathrm{~m}$ high and saturated watering from the floor to a height of $1 \mathrm{~m}$. Soil moisture was monitored using a soil environment meter (DECAGON, Em50, USA), and in the event of a decrease in soil moisture due to the atmospheric environment, proper soil moisture was restored using drip irrigation. The degree of experimental error due to natural environment stress was measured. Environmental data from the drought field (Additional file 1: Fig. S1) increased data reliability. An irrigation meter was installed in the drought field by the development of the irrigation system, and irrigation amounts were compared from the time of rice transplantation to harvest (146 days). Irrigation field irrigation flows were measured to be $106,100 \mathrm{~m}^{3}(75.7 \times 8.0 \times 1.2 \times 146$ days $)$ and $13,012 \mathrm{~m}^{3}$ for the drought field.

\section{Agronomic characteristics}

We measured culm length, panicle length, tiller number on yellow ripe stage, and recorded heading date based on a rate of $50 \%$ heading plants per line. Seed traits of length, width, and thickness were measured 
three times for 50 seeds per line using a vernier caliper (MITUTOYO, CD-15CP, Japan). The 1000-grain weight was measured three times by 1000 seeds, counted using an auto grain counter (Multi auto counter, WAVER, Japan), and weighed using an electronic scale (OHAUS, ARD120). Near-infrared spectroscopy (Kett, AN-820, Japan) was used to analyze the contents of amylose, protein, and moisture in brown and milled rice.

Germination rate was measured three times for 50 seeds per line. After incubation at $50{ }^{\circ} \mathrm{C}$ for 5 days to break dormancy, incubate at $28{ }^{\circ} \mathrm{C}$ for 15 days, and the appearance of shoots or roots of $2 \mathrm{~mm}$ or more was recorded as germination.

\section{Assessment of weediness potential}

The shattering property, viviparous germination, and germination are such phenotypes. Shattering is falling of a seed falling from a panicle spike. Shattering properties that are too strong increase the loss of yields and increase the number of seeds lost on land. In other words, the possibility of unintended natural release also increases. Cultivated rice has moderately weakened these shattering properties through long-term traditional breeding or short-term molecular breeding [16]. However, when natural hybridization occurs in a gene pool with high heterozygosity, or if foreign genes are inserted by molecular breeding methods, phenotypic changes can occur. This experiment compared the shattering properties between testing varieties to look for differences in gene flow probability. The primary branch of panicle 50 days after heading was sampled to maintain a water content of $12-15 \%$. Using a strain gauge (IMADA, DPS-5, Japan), pulling strength was measured parallel to the branch axis, and bending strength was measured by applying a force in the vertical direction. We measured 20 seeds per panicle, the branches were divided into four parts by location, and the intensity of 5 seeds per part was measured. The viviparous property is also a phenotypic characteristic of wild rice. Viviparous seeds germinate in the spike that is not shattered by continuous rainfall, lack of sunshine, and high relative humidity between the yellow ripe stage and full ripe period. This feature is an advantage in abnormal climatic phenomena, but results in a decreased yield due to nutrient loss and tissue changes in embryos and endosperm. In order to measure viviparous germination, samples were collected three times every 15 days starting 50 days after heading from the tested varieties and covered with cotton wool and watered and incubated in trays $(36 \times 26 \times 12 \mathrm{~cm})$ kept in the dark at $25^{\circ} \mathrm{C}$. Viviparous germination was recorded 15 days after treatment.

\section{Survivability in the natural environment}

Natural cold treatment seed viability tests were conducted to measure survivability in the natural environment of host plant Ilmi and GM plant HV. Three repeat test groups of 100 grains pretreated for 5 days in a $50{ }^{\circ} \mathrm{C}$ incubator are wintered at 4 depths (surface, 10, 20, and $30 \mathrm{~cm}$ ) in the soil for 150 days from November of the previous year to March of the examination year. The peeled seeds are immersed in distilled water at $40{ }^{\circ} \mathrm{C}$ for $1 \mathrm{~h}$. After immersion, it is cut longitudinally through the center of the embryonic axis and immersed in triphenyl tetrazolium chloride solution in the concentration of $0.25 \%$ and incubated at $35{ }^{\circ} \mathrm{C}$ for $1 \mathrm{~h}$ [17]. Seed vitality was determined by observing the degree and morphology of the embryo [18].

\section{Environmental release hazard screening}

HV lines contain a gene encoding phosphinothricin acetyltransferase (PAT), making them resistant to the herbicide glufosinate ammonium [19]. In this experiment, a horizontal gene transfer test was performed using a SeedChek ${ }^{\circledR}$ LL (7800019, ROMER, USA) containing a specific antibody binding to this protein. The leaves of 24 weeds were collected at $10-\mathrm{m}$ intervals up to $30 \mathrm{~m}$ around the GMO field, and ground in $0.5 \mathrm{ml}$ distilled. SeedChek ${ }^{\circledR}$ LL was immersed in the sample mixture to check whether the test line and control line were stained. To confirm vertical gene transfer, Ilmi was planted in 8 directions around the HV23 group and grown for a year, and the degree of transfer of the inserted gene by pollen was measured. Ilmi seeds arranged in 8 directions were harvested and grown in a glass greenhouse. Genetic transfer was measured by recording the surviving plants after treatment with $0.25 \%$ of a glufosinate ammoniumbased herbicide (Bayer, Basta, Germany) in the three-leaf stage [20].

\section{Data preprocessing and analysis}

All experimental data were analyzed using SPSS (IBM, IBM SPSS Statistics 25, USA). All raw data were preprocessed by removing outliers using a box plot and Dixon $Q$ test. Processed data of 8 pedigrees in the same environment are grouped at a significance level of 5\% using DMRT (Duncan multiple range test). Ilmi and HV lines were analyzed using independent $t$-tests to test phenotypic plasticity in different environments.

\section{Results}

\section{Comparison of agronomic characteristics}

The agronomic characteristics of GM strains HV8 and HV23, and parent plant Ilmi were measured in drought and irrigation fields. The heading date showed no 
significant difference results in all experimental groups except that HV8 and HV23 in the 2019 drought condition were delayed by 4 and 5 days compared to Ilmi. Culm length showed no significant difference in all experimental groups except that HV23 increased by an average of $5.2 \mathrm{~cm}$ compared to Ilmi under irrigation conditions in 2019. Under drought conditions, the tiller number increased in 2018 and 2019 in the HV8 and HV23 versus Ilmi, and the maximum average tiller number increased by 1.1. The average yields of HV8 and HV23 were higher than Ilmi in the irrigation environment, but there was no significant difference after the post hoc analysis of eight pedigrees. The most notable change was the increased yield of HV8 and HV23 under drought conditions, which not only produced higher yields versus Ilmi across both study years, but also increased the maximum average yield by $84.7 \%$ in 2018 (Additional file 1: Table S1).

The 1000-grain weights did not significantly differ between Ilmi, HV8, and HV23 at $19.7 \pm 0.06,19.6 \pm 0.35$, and $20.2 \pm 0.06 \mathrm{~g}$ under irrigation conditions in 2018. The same result was seen in all experimental groups (Additional file 1: Table S2). Phenotypic plasticity, which represents phenotype variation according to the environment, was not observed in 1000-grain weights of HV8 in 2018 or HV23 in 2019 (Fig. 1a, b). Regression analysis of 1000grain weight and volumetric water content showed positive trends and increasing slopes from HV8 to Ilmi and HV23.

DMRT showed no significant difference between the Ilmi and HV lines in grain shape traits like length,
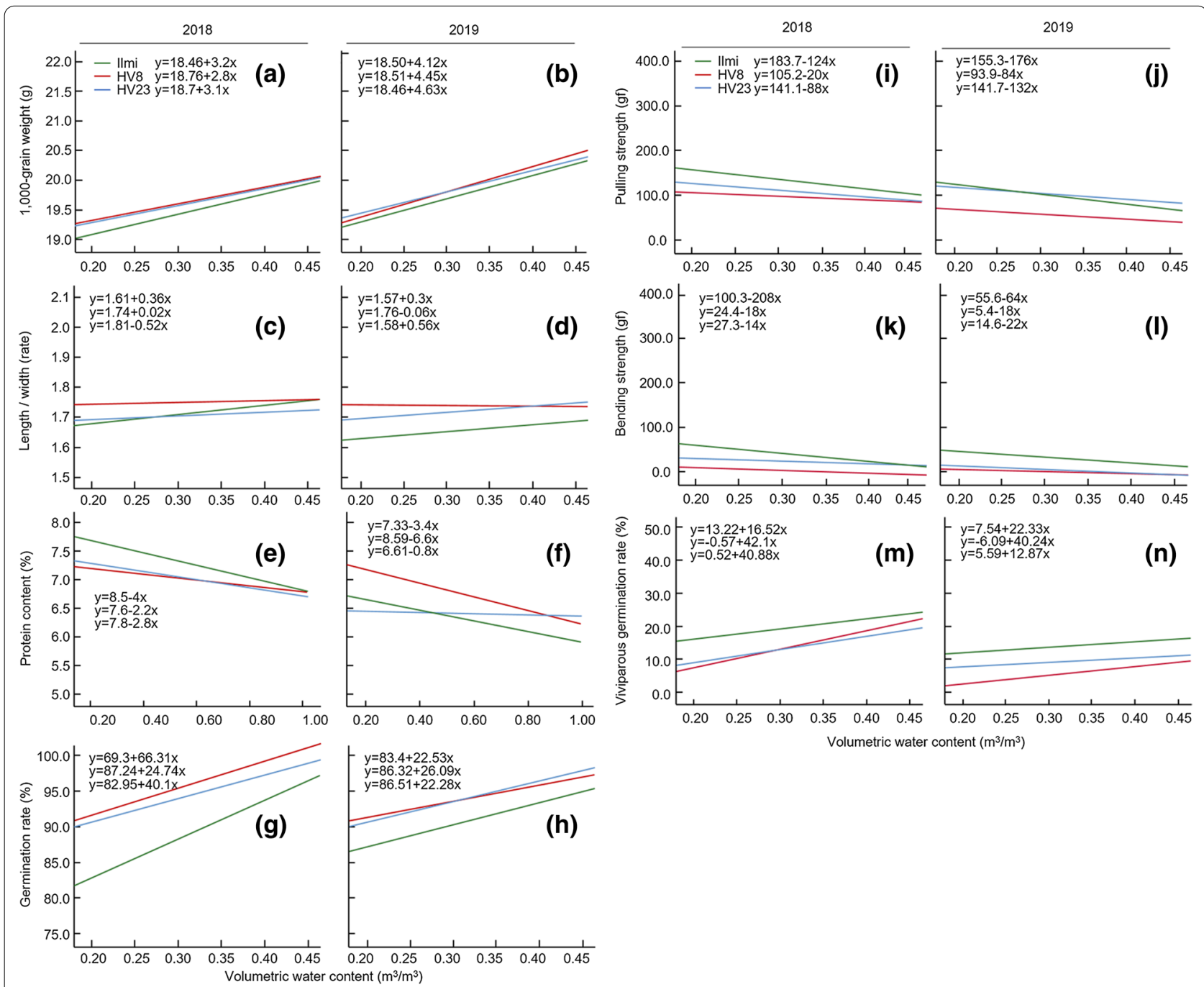

Fig. 1 Regression analysis plot for weediness testing of GM (HV8 and HV23) and non-GM (IImi) rice in 2018 and 2019. Regression analysis of the a 1000-grain weight in 2018, b 1000-grain weight in 2019, c length-to-width ratio in 2018, d length-to-width ratio in 2019, e seed protein content in $2018, \mathbf{f}$ seed protein content in $2019, \mathbf{g}$ germination rate in $2018, \mathbf{h}$ germination rate in 2019 , i pulling strength in $2018, \mathbf{j}$ pulling strength in $2019, \mathbf{k}$ bending strength in 2018, I bending strength in 2019, $\mathbf{m}$ viviparous germination rate in 2018, $\mathbf{n}$ viviparous germination rate in 2019 
width, thickness, and length-to-width ratio (Additional file 1: Table S3). HV8 showed no phenotypic plasticity for the length-to-width ratio in 2018 and HV23 in 2019. In 2018, HV23 showed a significant difference at the $10 \%$ level, although the threshold for significance for this study was 5\% (Fig. 2). Regression analysis of length-to-width ratio and volumetric water content showed increasing trends and greater absolute values of the slope from HV23 to HV8 and Ilmi (Fig. 1c, d).

Nutrient content was compared and analyzed in brown rice of GM rice and non-GM rice (Additional file 1: Table S4). In the irrigation field in 2018 and 2019, the nutrient content of both GM rice and non-GM rice was the same. Also, the protein, amylose, and moisture of GM rice and non-GM rice grown in drought field were the same (Fig. 3).

The content of amylose, protein, and moisture were analyzed in milled rice of GM rice and non-GM rice (Additional file 1: Table S5). When the nutrient content of milled rice was compared between GM rice and non-GM rice, it was the same in both irrigation field and drought field (Fig. 1e, f). In average time to germination, there was no significant difference between Ilmi and HV lines were recorded in all experimental groups. In all experimental groups except HV23 under irrigation conditions in 2018 and 2019, the HV lines demonstrated a greater average number of days to germination than Ilmi. Under irrigation conditions in 2018, HV8 had a higher germination rate than Ilmi,
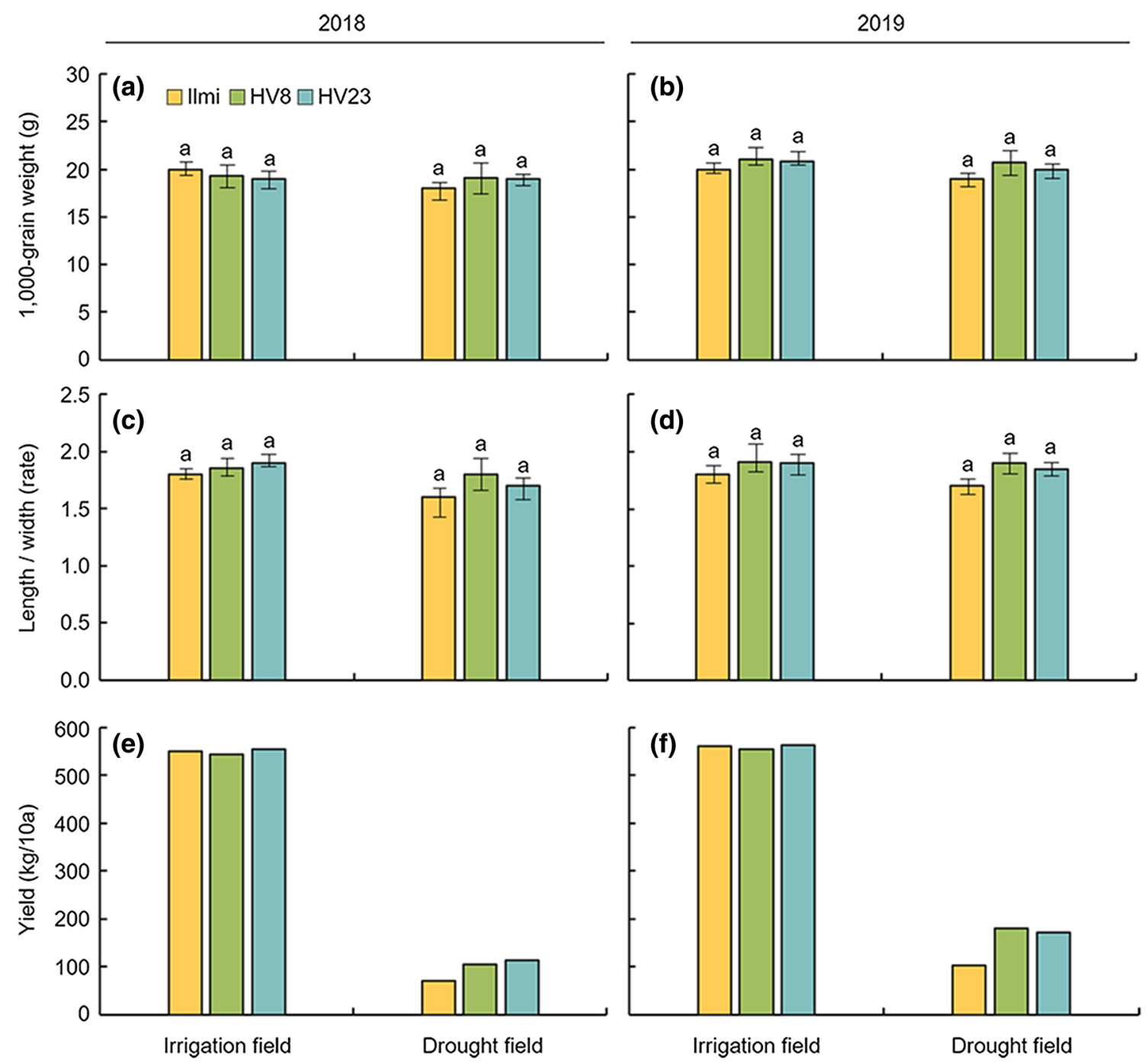

Fig. 2 Comparison of a 1000-grain weights in 2018, b 1000-grain weights in 2019, c grain length/width rate in 2018, d grain length/width rate in 2019, e yield in 2018, f yield in 2019 of GM (HV8 and HV23) and non-GM (IImi) rice in different environments 


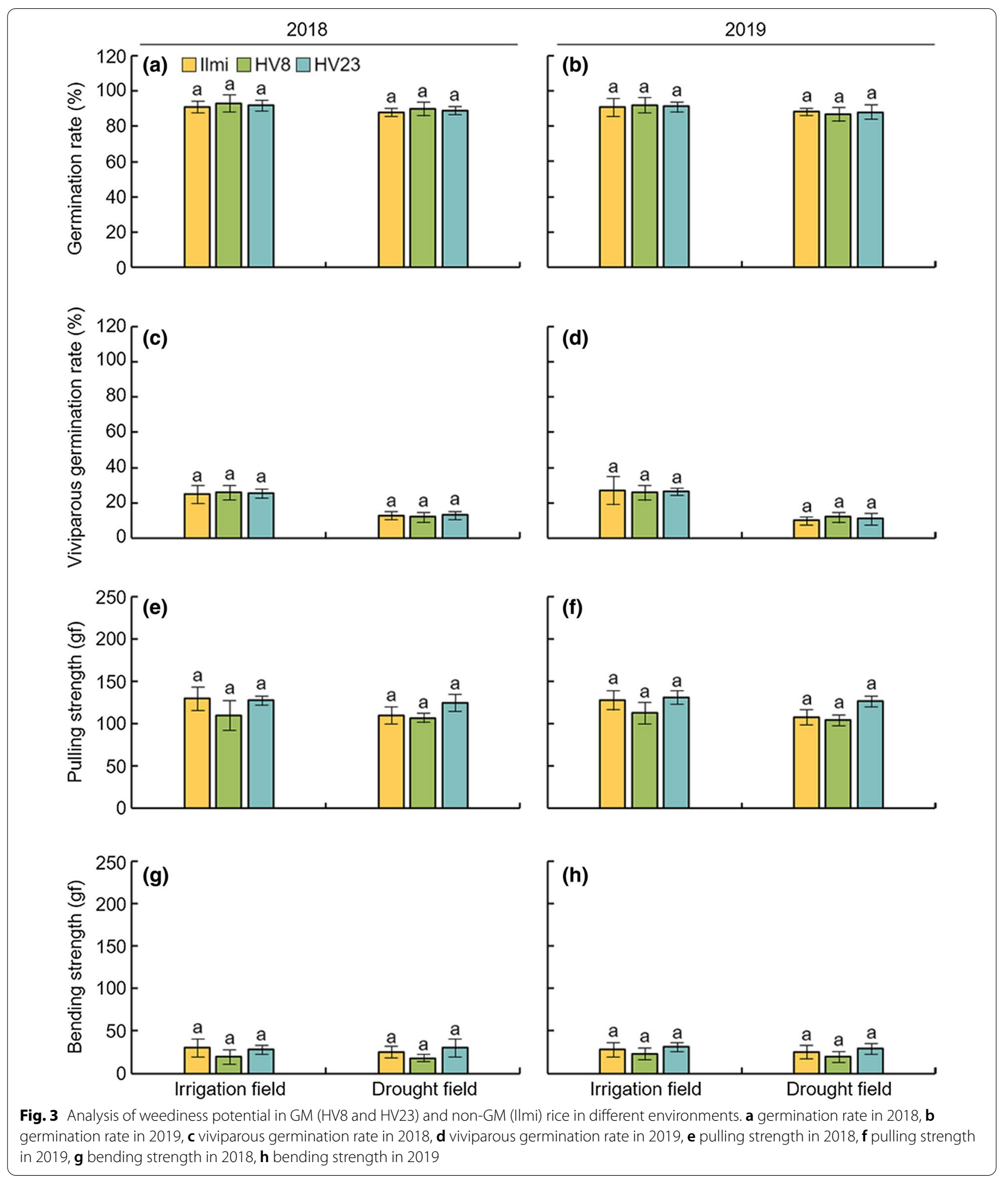

but all other experimental groups did not record significant differences between Ilmi and HV lines (Additional file 1: Table S6). As a result of regression analysis of the germination rate and volumetric water content, the two values are positively correlated in the HV lines, a negative trend in Ilmi, and increasing absolute 
values of the slope were recorded in HV8, HV23, and Ilmi (Fig. 1g, h).

\section{Assessment of weediness potential}

Weediness potential can be an indicator of how much the genetic material of rice spreads in various environments. In 2018, the pulling strength (gf) of Ilmi, HV8, and HV23 in the irrigation field was $130.6 \pm 18.5,110.7 \pm 21.4$, $128.4 \pm 15.8$ gf, respectively, and the bending strength (gf) was $25.4 \pm 5.8,18.9 \pm 9.2,30.9 \pm 8.6$ gf, respectively. Pulling and bending strength in the irrigation field were the same for HV line, GM rice and Ilmi, non-GM rice, without significant difference. In the drought field, the pulling strengths (gf) of Ilmi, HV8, and HV23 were $110.7 \pm 19.8,107.2 \pm 20.6,125.5 \pm 16.2$ gf, respectively, and the bending strength (gf) was $25.5 \pm 6.6,18.4 \pm 10.9$, and $30.8 \pm 9.4$ gf, respectively. In the drought field, the pulling strength and bending strength of GM rice and non-GM rice were the same (Fig. 3). In 2019, the pulling strength (gf) of Ilmi, HV8, and HV23 in the irrigation field was $128.1 \pm 18.7,113.0 \pm 22.8,131.3 \pm 18.3$ gf, respectively, and the bending strength (gf) was $28.3 \pm 6.9$, $23.7 \pm 9.4,31.7 \pm 8.6$ gf, respectively. Pulling and bending strength in the irrigation field were the same for $\mathrm{HV}$ line, GM rice and Ilmi, non-GM rice, without significant difference. In the drought field, the pulling strength (gf) of Ilmi, HV8, and HV23 were 108.8 $\pm 17.9,105.1 \pm 19.2$, $127.1 \pm 18.7 \mathrm{gf}$, respectively, and the bending strength (gf) was $25.7 \pm 9.3,20.2 \pm 8.2$, and $29.3 \pm 8.4$ gf, respectively. In the drought field, the pulling strength and bending strength of GM rice and non-GM rice were the same (Additional file 1: Table S7). As a result of regression analysis of pulling strength and volumetric water content, the two values are negatively tendency, and greater absolute values of the slope were recorded in the order of Ilmi, HV8, and HV23 (Fig. 1i, j). Also, as a result of regression analysis of bending strength and volumetric water content, the two values are positively tendency, and greater absolute values of the slope were recorded in the order of HV8, Ilmi, and HV23 (Fig. 1k, m).

The average spikelets/panicle data of all experimental groups did not show a significant difference between the Ilmi and HV lines. The viviparous germination rate data of all experimental groups did not show a significant difference between the Ilmi and HV lines (Additional file 1: Table S8). The phenotypic plasticity of the viviparous germination rate, according to the environment in HV23, was none or less than that of Ilmi and
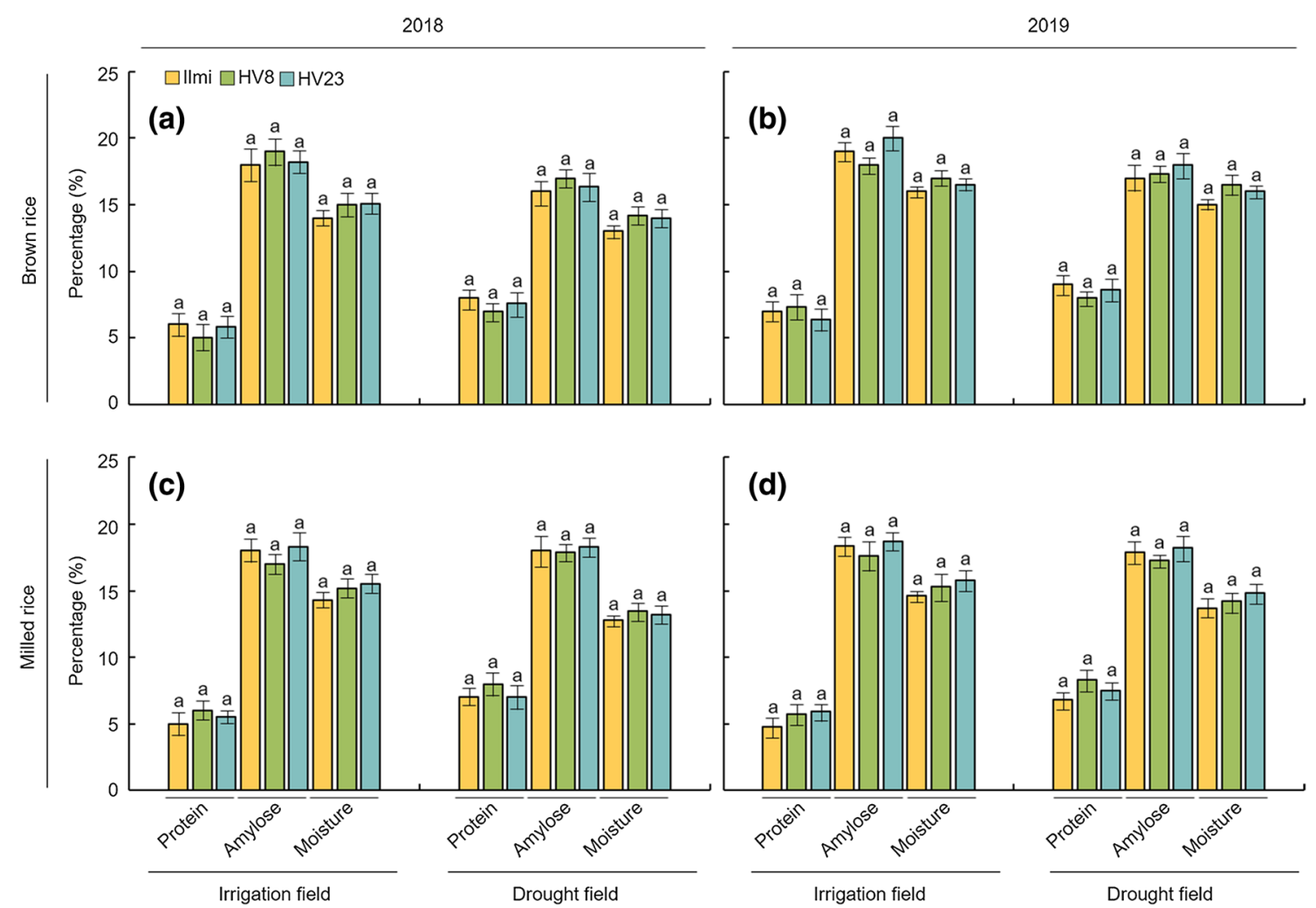

Fig. 4 Compare brown rice and milled rice protein, amylose, and moisture contents of GM (HV8 and HV23) and non-GM (IImi) rice in different environments. a Comparative analysis of protein, amylose, moisture content in Brown rice in 2018. b Comparative analysis of protein, amylose, moisture content in Brown rice in 2019. c Comparative analysis of protein, amylose, and moisture content in Milled rice in 2018. d Comparative analysis of protein, amylose, and moisture content in Milled rice in 2019 
HV8 (Fig. 4). As a result of regression analysis of the viviparous germination rate and volumetric water content, the two values are positively tendency, and greater absolute values of the slope were recorded in the order of HV8, Ilmi, and HV23 (Fig. 1n, l).

\section{Survivability in the natural environment}

The viability of natural cold treatment germination test was $0 \%$ in all experimental groups, which means that the GM rice is very unlikely to survive in the next year natural cold treatment (Additional file 1: Table S9).

\section{Environmental release hazard screening}

In the samples of heterogeneous plants collected at 24 places within $30 \mathrm{~m}$ around the GM filed, no gene transfer of bar gene was found (Fig. 5a, b and Additional file 1: Table S10). As a result of the vertical gene transfer test, no gene transfer by the bar gene was found in all experimental groups, after treatment with herbicides, the

(a)

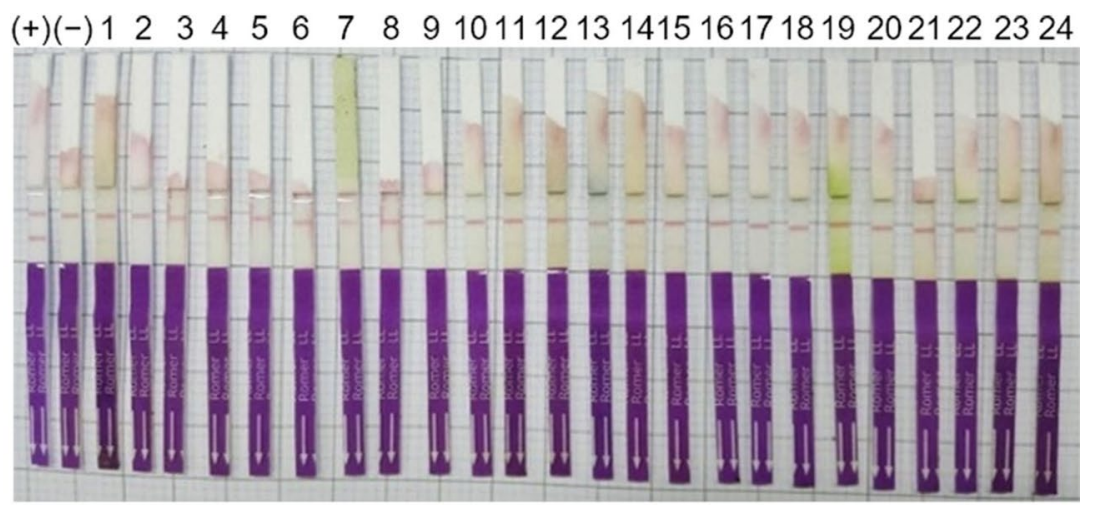

(b)

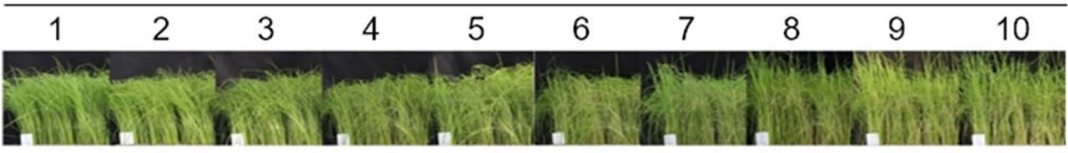

IImi (North-East)

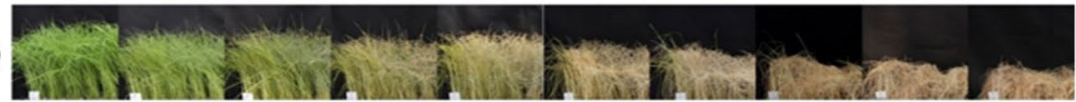

IImi (South-West)

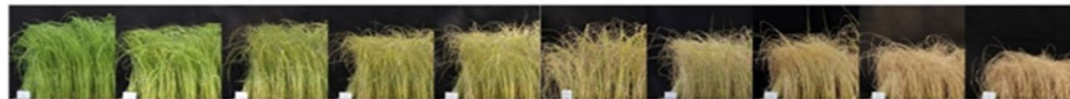

Ilmi (North-west)

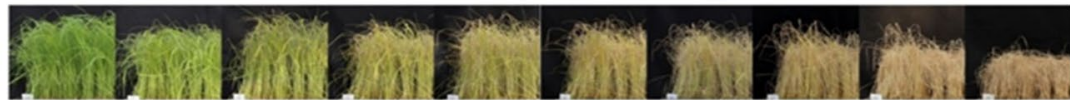

IImi (South-west)

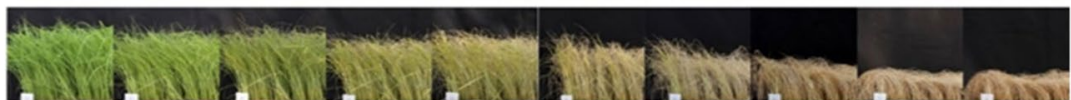

IImi (West)

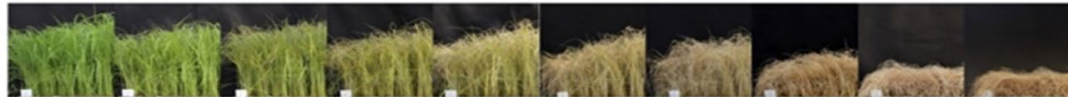

IImi (East)

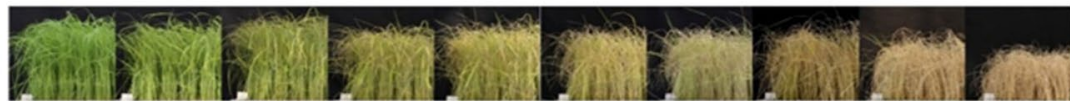

IImi (North)

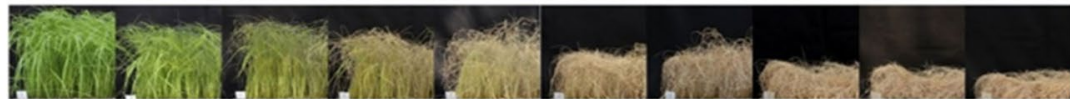

IImi (South)

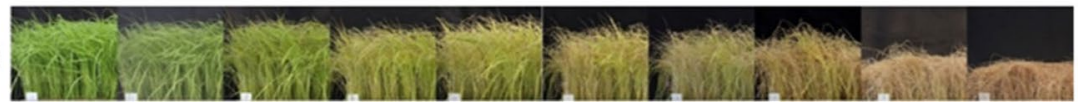

Fig. 5 Gene flow analysis of GM rice. a Horizontal gene transfer test with the use of bar gene targeting lateral flow device. $\mathbf{b}$ vertical gene transfer test with the use of herbicide resistance test 
result of the follow-up test of the appearance change of the experimental group. Two days after herbicide treatment, the color of the leaves changed from dark green to light green, and Ilmi gradually died. On the 3rd day, the leaves became narrow. On the fourth day, the color of the leaves turned brown and became worse by 7 days. There is no noticeable difference in direction. After the second herbicide treatment, Ilmi rapidly began to wither with $100 \%$ withering in all directions on day 10 . On the other hand, HV23 did not affect herbicide treatment (Fig. 5 and Additional file 1: Table S11).

\section{Discussion}

The expression of unintentional phenotypes of GM plants and their impact on the environment are of common interest to the public and researchers. In this experiment, a great deal of effort was made to objectify the phenotypes expressed by 8 pedigrees in the same place (agricultural environment and surrounding natural environment) for 2 years. The world regulates and thoroughly manages GM crops through environmental risk assessment (ERA) developed to reduce anxiety about GM crops [21]. Although many GM crops have been safely grown and commercially available for more than 25 years now, there are still numerous concerns and negative comments [22]. Only laboratory research results have limitations in resolving the anxiety of environmental groups, and the results of conducting research in a practical environment through field experiments should be supported [23].

Environmental data were collected to analyze the environment for the gene transfer test of GM rice and the growth environment of all testing varieties, including GM rice. The error of gene transfer test caused by pollen infertility is very low because of the continuous hightemperature environment of more than $8 \mathrm{~h}$ and more than $35{ }^{\circ} \mathrm{C}$, which is likely to cause infertility in rice, did not occur for two consecutive years in this experiment. In daytime $16 \mathrm{~h}$ temperature at $37.5{ }^{\circ} \mathrm{C}$ and night temperature at $25{ }^{\circ} \mathrm{C}$, wind velocity above $1.5 \mathrm{~m} / \mathrm{s}$ induces pollen desiccating, causing a rapid decrease in fertility [24]. In the GMO field, the daytime temperature in 2018 and 2019 never exceeded $37.5^{\circ} \mathrm{C}$, so it is unlikely that the infertility rate would increase due to the wind. In the drought field constructed in this study, agricultural traits of GM rice and non-GM rice were compared and analyzed while maintaining only the minimum soil moisture required for rice growth. We confirmed that only $12.3 \%$ of irrigation flows in the drought field were from the drip irrigation versus the irrigation field. Rice fertility reaches a peak with daytime average temperatures of $30{ }^{\circ} \mathrm{C}$ on the heading date. When it is exposed to temperatures over $35{ }^{\circ} \mathrm{C}$ for more than $8 \mathrm{~h}$, anther vitality begins to drop [25]. At this time, high relative humidity reduces the pollen dispersion ratio and the possibility of pollination. The daily mean temperature in this study peaked at $30.1,29.0{ }^{\circ} \mathrm{C}$ average, $23.0 \pm 4.6{ }^{\circ} \mathrm{C}, 23.2 \pm 3.6{ }^{\circ} \mathrm{C}$ relative humidity, the average of $81.8 \pm 8.7 \%$, and $85.2 \pm 6.1 \%$. These characteristics represent a normal growth environment with a low possibility of infertility due to temperature and relative humidity. The highest rainfall was 68 and $79 \mathrm{~mm}$ per hour, but it was far less than the heavy rain warning level of $142 \mathrm{~mm}$. Wind direction and wind speed are for measuring gene mobility by pollen in the vertical gene transfer test field (Additional file 1: Fig. S1). The wind speed (Additional file 1: Fig. S2) is the highest wind speed of $4.4 \mathrm{~m} / \mathrm{s}$ and $4.3 \mathrm{~m} / \mathrm{s}$. The highest frequency of wind direction was $15.6 \%$ in the east-northeast wind in 2018 and $16.4 \%$ in the east wind in 2019. The results showed no significant difference between 2018 and 2019, with no environmental conditions that could cause pollen infertility.

The volumetric water content of the drought tolerance measurement greenhouse in 2018 and 2019 was 0.22 and $0.37 \mathrm{~m}^{3} / \mathrm{m}^{3}$, and the irrigation field recorded 0.44 and $0.42 \mathrm{~m}^{3} / \mathrm{m}^{3}$, so it is unlikely that water stress caused a delay in heading date. The minimum temperature of drought tolerance measurement greenhouse is 21.3 and $26.9{ }^{\circ} \mathrm{C}$ in 2018 and 2019 , which does not correspond to the low temperature which delays the heading date in rice [26]. The water in the silt has a net positive suction head from the water surface to a height of about $1000 \mathrm{~cm}$ by capillary action and a uniform hydraulic conductivity of $1 \times 10^{-5}$ up to $100 \mathrm{~cm}$ [27]. This phenomenon causes spontaneous irrigation, satisfies the minimum soil moisture required for the growth of rice, and creates a drought environment [28].

The expression of CaMsrB2 promotes the reverse reaction of reactive oxygen species production by drought stress to prevent oxidative stress, reduce protein and nucleic acid degradation, and lipid and membrane damage [29]. This enables normal growth and development even under drought stress, lowering the infertility rate of spikelets caused by drought stress [30, 31]. In this experiment, the tiller number recorded a significant difference between the Ilmi and HV lines in drought environments (Additional file 1: Table S1). There was no statistically significant difference shown by DMRT using 8 pedigrees, but the average spikelet/panicle values were higher in the HV lines than in Ilmi (Additional file 1: Table S8). This phenomenon can cause a significant difference in yield in a drought environment.

National regulations require the prevention of GMOs being released by humans or the environment until the safety of the biological and food products produced by genetic engineering has been scientifically proven. Therefore, verifying the spreading power of GMOs is an 
important task in environmental safety assessments. As a result of continued genetic variation and natural selection, wild rice has a favorable phenotype for gene spread [32].

In general, the 1000-grain weight does not significantly decrease until the soil moisture content drops to $25 \%$. Water stress increases the content of unfilled grains, but does not cause a significant change in the weight of a single seed. DMRT of 8 pedigrees for 1000 grain weight showed no significant difference between Ilmi and HV lines for two consecutive years in all environments, so HV lines are expected to have less reduction in 1000-grain weight due to water stress compared to Ilmi (Fig. 1). The length-to-width ratio is a physical shape characteristic related to 1000-grain weight. DMRT of 8 pedigrees for the length-to-width ratio showed no significant difference between the Ilmi and HV lines, so there was no change in grain shape characteristics as a result of the insertion gene.. Changes in rice quality due to water stress during the ripening period are generally expressed by increasing protein content, decreasing amylose content, and decreasing moisture content [33]. The change in nutrient contents recorded the same pattern as the result of the previous proof concept experiment in a drought environment, which means that sufficient water stress treatment was performed. The significant difference in protein content between Ilmi and HV lines is expected to be due to the reduction of oxidized methionine by the CaM$s r B 2$ gene [13]. The increase in the number of non-germinated seeds due to changes in the germination trait has a great influence on the yield reduction. However, in all experimental groups, HV lines did not record a significant difference in germination percentage for two consecutive years compared to Ilmi. Therefore, it can be expected that the inserted gene site of HV lines does not affect the gene locus related to germination. The strong shattering habit of rice means that it has great weediness potential. In this experiment, HV8 showed weaker bending strength than Ilmi, especially in a drought environment. This result not only increases the likelihood of unintentional gene release due to seed shattering in the natural environment, but also causes a decrease in yield. The increase of viviparous germination is explained by the weakening of dormancy and early ripening. Yield decreases when inert material is removed by meteorological disasters such as the rainy season and typhoons and becomes viviparous with high moisture and temperature. In this experiment, DMRT were performed for viviparous germination of 8 pedigrees, and no significant difference was found between Ilmi and HV lines. In the natural cold treatment germination test, which verifies survivability in the natural environment, the samples of all experimental groups did not record viability enough to ensure hastening of germination. These results explain that GM rice seeds introduced into nature due to unintentional release are highly likely to be culled due to the nature of the Korean season, which undergoes wintering after harvest.

Sometimes in GM crops, unintentional traits are expressed by exon site cleavage caused by the location of the foreign gene insertion[34]. Even if the foreign gene insertion occurs in an intron, the intron may serve as a regulator of gene expression [35]. Therefore, a continuous phenotype monitoring system has been used to raise awareness of safe GM crops. As a result of the horizontal gene transfer test, no intercross occurred within a $30 \mathrm{~m}$ radius from the GM plants isolation field. Hybridization by pollen did not occur in the vertical gene transfer test, which is expected to be due to the low probability of natural crossing of rice [36]. Through all the data in this experiment, it was possible to prove that there was no difference in phenotypic characteristics between GM rice and host plant except for intentional changes in a trait, and the risk of environmental release was very low.

\section{Conclusions}

Through the environmental risk assessment of HV8 and HV23 of GM rice with the drought resistance gene inserted, the effects of GM rice on humans and the environment were confirmed through objective indicators. Environmental data were accumulated by recording wind direction, wind speed, precipitation, daily average temperature, and relative humidity of the entire GM planting area. A system was established to maintain environmental conditions in a dry-resistant test greenhouse, and based on this, the degree of error in the experiment due to extreme environments was limited. The expression of unintended traits was detected through the comparison of various phenotypes, and the degree of intentional expression was evaluated. The target trait, yield, was $88.9 \pm 3.1 \mathrm{~kg} / 10$ a for Ilmi in drought conditions in 2018. However, HV8 was $164.2 \pm 4.1 \mathrm{~kg} / 10 \mathrm{a}$, which is $84.7 \%$ higher than that of Ilmi. In drought conditions in 2019 , Ilmi was $122.0 \pm 2.8 \mathrm{~kg} / 10 \mathrm{a}$, and HV23 was $172.7 \pm 7.1 \mathrm{~kg} / 10 \mathrm{a}$, which was $41.6 \%$ higher for HV23 than Ilmi. There was no gene mobility of GM rice due to intentional or unintentional release, as verified by the natural environment viability and gene mobility tests.

\section{Supplementary Information}

The online version contains supplementary material available at https://doi. org/10.1186/s12302-021-00516-9.

Additional file 1: Figure S1. Drought tolerance test greenhouse and vertical gene transfer test field. Figure S2. Daily mean various environmental 
factor from august to September in 2018 and 2019. Table S1. Agricultural characteristics by environmental condition. Table S2. Grain traits each of environmental conditions. Table S3. Grain shape traits each of environmental conditions. Table S4. Brown rice nutrient content by environmental condition. Table S5. Milled rice nutrient content by environmental condition. Table S6. Germination traits by environmental condition. Table S7. Shattering traits by environmental condition. Table S8. Viviparous germination by environmental condition. Table $\mathbf{S 9}$. After-wintering seed viability. Table S10. Horizontal gene transfer. Table S11. Vertical gene transfer.

\section{Acknowledgements}

This work was supported from agency of LMO environmental risk assessment (PJ015787022021), Rural Development Administration, Republic of Korea.

\section{Authors' contributions}

DWJ, JRP planned and conceptualized the study; JRP, YHJ conducted the experiments; EGK performed statistical analyses; DWJ, JRP performed chemical and biochemical analyses; DWJ, JRP wrote the first draft; JRP made praphs; KMK supervised this project. All authors read and approved the final manuscript.

\section{Funding}

None.

\section{Availability of data and materials}

The datasets used and/or analyzed during the current study are available from the corresponding author on reasonable request.

\section{Declarations}

\section{Ethics approval and consent to participate}

Not applicable.

\section{Consent for publication}

Not applicable.

\section{Competing interests}

The authors declare that they have no competing interests.

\section{Author details}

${ }^{1}$ Division of Plant Biosciences, School of Applied Biosciences, College of Agriculture and Life Science, Kyungpook National University, Daegu 41566, Korea. ${ }^{2}$ Coastal Agriculture Research Institute, Kyungpook National University, Daegu, Korea. ${ }^{3}$ Biosafety Division, National Institute of Agricultural Sciences, Rural Development Administration, Jeonju, South Korea.

Received: 27 April 2021 Accepted: 12 June 2021

Published online: 23 June 2021

\section{References}

1. Serraj R, McNally KL, Slamet-Loedin I et al (2011) Drought resistance improvement in rice: an integrated genetic and resource management strategy. Plant Prod Sci 14:1-14

2. Nam WH, Hayes MJ, Svoboda MD et al (2015) Drought hazard assessment in the context of climate change for South Korea. Agric Water Manag 160:106-117. https://doi.org/10.1016/j.agwat.2015.06.029

3. Soren KR, Ali K, Tyagi V, Tyagi A (2010) Recent advances in molecular breeding of drought tolerance in rice (Oryza sativa L.). Indian J Biotechnol 9:233-251

4. Strauss DM (2006) The international regulation of genetically modified organisms: importing caution into the U.S. food supply. Food Drug Law J 61:167-196

5. Lu BR, Snow AA (2005) Gene flow from genetically modified rice and its environmental consequences. Bioscience 55:669-678. https://doi.org/10. 1641/0006-3568(2005)055[0669:GFFGMR]2.0.CO;2
6. Hall C, Moran D (2006) Investigating GM risk perceptions: a survey of antiGM and environmental campaign group members. J Rural Stud 22:29-37. https://doi.org/10.1016/j.jrurstud.2005.05.010

7. Mizuguti A, Ohigashi K, Yoshimura Y et al (2010) Hybridization between GM soybean (Glycine max (L.) Merr.) and wild soybean (Glycine soja Sieb. et Zucc.) under field conditions in Japan. Environ Biosafety Res 9:13-23. https://doi.org/10.1051/ebr/2010004

8. Marotti I, Whittaker A, Benedettelli S et al (2020) Evaluation of the propensity of interspecific hybridization between oilseed rape (Brassica napus L.) to wild-growing black mustard (Brassica nigra L.) displaying mixoploidy. Plant Sci 296:110493. https://doi.org/10.1016/j.plantsci.2020.110493

9. Schulman $\mathrm{AH}$ (2020) The impact of GM crops on agriculture. Elsevier Inc, Amsterdam

10. Hwang H, Nam SJ (2021) The influence of consumers' knowledge on their responses to genetically modified foods. GM Crop Food 12:146-157. https://doi.org/10.1080/21645698.2020.1840911

11. Bradshaw AD (1965) Evolutionary significance of phenotypic plasticity in plants. Adv Genet 13:115-155

12. Nonhebel S (1993) The importance of weather data in crop growth simulation models and assessment of climatic change effects. Nonhebel

13. Oh S-K, Baek K-H, Seong ES et al (2010) CaMsrB2, pepper methionine sulfoxide reductase $B 2$, is a novel defense regulator against oxidative stress and pathogen attack. Plant Physiol 154:245-261

14. Siddiqui ZS, Cho J-I, Kwon T-R et al (2014) Physiological mechanism of drought tolerance in transgenic rice plants expressing Capsicum annuum methionine sulfoxide reductase B2 (CaMsrB2) gene. Acta Physiol Plant 36:1143-1153

15. Dhungana SK, Kim BR, Son JH et al (2015) Comparative study of CaMsrB2 gene containing drought-tolerant transgenic rice (Oryza sativa L.) and non-transgenic counterpart. J Agron Crop Sci 201:10-16. https://doi.org/ 10.1111/jac. 12100

16. Li C, Zhou A, Sang T (2006) Rice domestication by reducing shattering. Science 311:1936-1939. https://doi.org/10.1126/science.1123604

17. Carvalho IL, Meneghello GE, de Tunes LM et al (2017) Methodological adjustments to the tetrazolium test in rice seeds. J Seed Sci 39:41-49

18. Cottrell HJ (1948) Tetrazolium salt as a seed germination indicator. Ann Appl Biol 35:123-131. https://doi.org/10.1111/j.1744-7348.1948.tb07355.x

19. Hérouet C, Esdaile DJ, Mallyon BA et al (2005) Safety evaluation of the phosphinothricin acetyltransferase proteins encoded by the pat and bar sequences that confer tolerance to glufosinate-ammonium herbicide in transgenic plants. Regul Toxicol Pharmacol 41:134-149. https://doi.org/ 10.1016/j.yrtph.2004.11.002

20. Rathore KS, Chowdhury VK, Hodges TK (1993) Use of bar as a selectable marker gene and for the production of herbicide-resistant rice plants from protoplasts. Plant Mol Biol 21:871-884

21. EFSA Panel on Genetically Modified Organisms (GMOs) (2011) Guidance for risk assessment of food and feed from genetically modified plants. EFSA J 9:2150. https://doi.org/10.2903/j.efsa.2011.2150

22. Waters S, Ramos A, Culler AH, Hunst P, Zeph L, Gast R, Mahadeo D, Sottosanto J, Huber S, Shan G, Chakravarthy S (2021) Recommendations for science-based safety assessment of genetically modified (GM) plants for food and feed uses. J Regul Sci. 9(1):16-21

23. Bachman PM, Anderson J, Burns A et al (2021) Data transportability for studies performed to support an environmental risk assessment for genetically modified (GM) crops. J Regul Sci 9:38-44

24. Mitsuaki (2002) NIl-electronic library service. Chem Pharm Bull 57:364-370

25. Hjältén J, Lindau A, Wennström A et al (2007) Unintentional changes of defence traits in GM trees can influence plant-herbivore interactions. Basic Appl Ecol 8:434-443

26. Luan W, Chen H, Fu Y et al (2009) The effect of the crosstalk between photoperiod and temperature on the heading-date in rice. PLoS ONE 4:e5891

27. Lu N, Likos WJ (2004) Rate of capillary rise in soil. J Geotech Geoenviron Eng 130:646-650

28. Bouman BA (2001) ORYZA2000: modeling lowland rice. IRRI, Los Banos

29. Moslen MT (1994) Reactive oxygen species in normal physiology, cell injury and phagocytosis. In: Armstrong D (ed) Free radicals in diagnostic medicine. Springer, Boston, pp 17-27

30. Elsayed Al, Rafudeen MS, Golldack D (2014) Physiological aspects of raffinose family oligosaccharides in plants: Protection against abiotic stress. Plant Biol 16:1-8. https://doi.org/10.1111/plb.12053 
31. O'Toole JC, Moya TB (1981) Water deficits and yield in upland rice. F Crop Res 4:247-259

32. Darwin CR (1872) On the Origin of Species (Notes). John Murray 5:318-319

33. Pandey A, Kumar A, Pandey DS, Thongbam PD (2014) Rice quality under water stress. Indian J Adv Plant Res 1:23-26

34. Hjältén J, Lindau A, Wennström A et al (2007) Unintentional changes of defence traits in GM trees can influence plant-herbivore interactions. Basic Appl Ecol 8:434-443. https://doi.org/10.1016/j.baae.2006.09.001
35. Rose AB (2004) The effect of intron location on intron-mediated enhancement of gene expression in Arabidopsis. Plant J 40:744-751. https://doi. org/10.1111/j.1365-313X.2004.02247.x

36. Sahadevan BYPC, Namboodir KMN (1963) Natural. 176-185

\section{Publisher's Note}

Springer Nature remains neutral with regard to jurisdictional claims in published maps and institutional affiliations.

\section{Submit your manuscript to a SpringerOpen ${ }^{\circ}$ journal and benefit from:}

- Convenient online submission

- Rigorous peer review

- Open access: articles freely available online

- High visibility within the field

- Retaining the copyright to your article

Submit your next manuscript at $\boldsymbol{\nabla}$ springeropen.com 